\section{European inter-comparison studies as a tool for perfecting irradiated food detection methods}

Grzegorz Piotr Guzik (D), Jacek Michalik

\begin{abstract}
In this paper, we present the results of inter-comparison studies on identification of irradiated food carried out by the leading European laboratories from 1991 to 2018. In 1990s, the Federal Institute for Health Protection of Consumers and Veterinary Medicine in Germany played the leading role in the organization of the inter-laboratory tests on this subject. At the beginning of the present century, the Spanish Agency for Food Safety and Nutrition and Food National Spanish Centre took over this role. In total, 47 international tests were carried out in which nearly 500 samples of alimentary products were analysed in 37 laboratories from 14 European countries. The tests were aimed at proving the reliability of analytical methods - thermoluminescence (TL), photostimulated luminescence (PSL), and electron paramagnetic resonance (EPR) spectroscopy - for identification of specific irradiated food products and to control the analytical skills and experience of participating laboratories. The results made possible a discussion on why some irradiated food samples are more difficult for identification. In general, the tests showed that TL measurements of products such as herbs, nuts, peppers, and raisins, and EPR studies of fish and chicken bones, fresh strawberries, and dried fruits could be used as reliable control methods. The challenge that control laboratories are facing now, is related to the identification of complex food products such as diet supplements or biopharmaceuticals, in which only some additives are irradiated.
\end{abstract}

Keywords: Detection • Inter-comparison tests $\bullet$ EPR $\bullet$ Irradiated food $\bullet$ PSL $\bullet$ TL

G. P. Guzik ${ }^{\bowtie}$, J. Michalik ${ }^{\bowtie}$

Institute of Nuclear Chemistry and Technology

Dorodna 16 Str., 03-195 Warsaw, Poland

E-mails: g.guzik@ichtj.waw.pl, j.michalik@ichtj.waw.pl

Received: 21 January 2021

Accepted: 6 May 2021

\section{Introduction}

Since ancient times, people tried to prolong food durability because fresh food was not easily accessible and is prone to undergo rapid deteriration. The previous methods of food conservation, such as drying in air, boiling, baking, smoking, and freezing, in the second half of the 20th century used the radiation pasteurization technique, which involves irradiation of food with gamma rays or electron beams generated in linear accelerators. Radiation effectively eliminates all pathogens present in agricultural and food products, as well as in processed food. Universal studies carried out in leading nutrition centres for many years proved that irradiated food is safe for human health. Based on these opinions, the FAO/WHO Expert Commission in 1983 developed the Codex Alimentarius, Volume $X V$, which recommended food irradiation as a safe and efficient method of food conservation [1].

However, the influential consumer groups were not completely satisfied with that recommendation and demanded that irradiated food should be labelled. In 1988, during the Geneva Conference on the Acceptance, Control and Trade of Irradiated Food, the representatives of almost hundred

0029-5922 @ 2021 The Author(s). Published by the Institute of Nuclear Chemistry and Technology.

This is an open access article under the CC BY-NC-ND 4.0 licence (http://creativecommons.org/licences/by-nc-nd/4.0/). 
countries of the world agreed on the "International Document on Food Irradiation," which was later accepted by the respective governments [2]. Under Section 36.5 of the document, the required control of irradiated food and the development of suitable identification methods of irradiated products are described. According to experts, the independent control system should facilitate the food trade and increase consumer confidence on the food control system. In 1999, the European Parliament voted down the obligatory legal regulations - directives 1992/2/EC and 1992/3/EC - concerning food irradiation. According to them, only dried herbs, spices, and vegetables can be irradiated, and the irradiated food products have to be labelled.

Outside the EU, many other irradiated food products such as fruits, fresh vegetables, grains and grain products, legume seeds, tea and coffee, nuts, and also fishes, seafood, poultry, and meat are made available for sale. The radiation treatment of food ensures the profound reduction of microbiological flora, increasing food quality and safety, as well as storage time. Consumers can choose between irradiated and non-irradiated grocery products. However, the radiation-treated food can only enter into the market if the product is labelled as irradiated.

According to EU directives, every analytical laboratory appointed for identification of irradiated food should participate periodically in interlaboratory comparisons based on ten analytical methods standardized by the Committee of European Normalization (CEN). They can be divided into three groups. The physical methods measure the changes in electrical conductivity, viscosity, and thermal properties resulting from structural modifications on a molecular level. The chemical and biological methods are based on the identification of trace amounts of radiation products. In the spectroscopic methods - thermoluminescence (TL) [3], photostimulated luminescence (PSL) [4], and electron paramagnetic/spin resonance (EPR/ESR) spectroscopy [5-7] - the stable centers with excess electrons produced by ionizing radiation are identified. In laboratory practice, the methods based on EPR, TL, and PSL are the most frequently used ones.

\section{Inter-comparison studies organized by the Federal Institute for Health Protection of Consumers and Veterinary Medicine}

The inter-comparison studies for identification of irradiated food were initialized in Europe by German laboratories in the early 1990s. In 1991, the Federal Institute for Health Protection of Consumers and Veterinary Medicine organized the test to control reliability of the TL method for identification of herbs and spices $[8,9]$. Six laboratories took part in that test analysing 12 samples, and all of them correctly recognized the irradiated and unirradiated samples [8]. In 1993, under supervision of the same institute, 14 participants analysed 18 different samples of herbs, spices, and spice mixes, and again, all laboratories made correct identifications [9].
The tests dedicated for TL identification of shrimp samples were organized in 1995 and 1997 with participation of 23 and seven laboratories, respectively. In total, 228 coded shrimp samples were studied, and only two samples were misidentified $[10,11]$. In 1997, the same institute organized the intercomparison studies concerned with TL identification of irradiated potatoes. The 22 laboratories analysed 220 samples of potatoes, which were unirradiated and irradiated with three different doses, and 216 samples were correctly identified. In general, the tests conducted in the 1990s confirmed very high reliability of the TL method in relation to different food products such as herbs, spices, and marine crustaceans $[3,12,13]$.

This is not true for the PSL method, which is cheap and easy to perform because it does not require the separation of minerals from food products. In 1998, two tests for PSL identification were carried out. In the first one, 400 different herbs, spices, and spice blends were analysed by eight laboratories. Only 345 samples were correctly identified [4]. In the second test, 75 samples of crustaceans and mollusks were studied by five laboratories, and all methods and samples used in the study were classified in a proper way [14]. This clearly shows that PSL methodology, although simple to perform, is suitable only to some types of food products, for example, such as shellfishes. Similarly, the TL methods cannot be used for all food products. For identification of irradiated food containing bones such as pork and beef meat, chickens and fishes, and also food products containing cellulose and crystalline sugars, the European Standards recommend EPR spectroscopy. Using the EPR technique, the long-lived paramagnetic centers and radicals generated by ionizing radiation and stabilized in solid parts of food are measured. This method is fast and usually does not require the measurements of a control (non-irradiated) sample. Additionally, the samples can be measured as delivered without any tedious separation procedure.

Over last the 30 years, a dozen EPR inter-laboratory tests had been carried out in order to estimate the reliability of the EPR technique for identification of different food samples.

In the early 1990s, two series of large tests based on EPR measurements were organized. In the first one, the aim was to identify the samples of irradiated beef, chicken, and trout bones. Altogether, 192 samples were studied by EPR in 21 laboratories, and only seven samples were incorrectly assigned [13]. Based on the positive results of the tests, the European standard EN 1786:2000 was worked out [7]. In the second test, 21 laboratories carried out the EPR measurements to identify irradiated pistachio nuts, pepper powders, and fresh strawberries [15]. Pistachio nuts were analysed in two rounds. In the first round, for 68 analysed samples, 17 results were incorrect, whereas in the second round, only two samples were wrongly identified among 160 samples studied $[16,17]$. The EPR indicator of fresh strawberries is a stable singlet with satellite lines in the distance of $6 \mathrm{mT}$, which is induced by radiation of small black seeds on the surface of strawberries. In 
spite of that, for 184 tested samples of fresh strawberries, only nine samples were identified incorrectly [6]. The EPR signal in irradiated pepper powder comes from cellulose radical and has low intensity. However, it turned out that the identification reliability of pepper powder by the EPR technique is very high - for 160 samples, only one was incorrectly assigned [17].

At the beginning of the 1990s, the European institutions responsible for food safety took up the problem of dried fruits such as papayas, mangoes, figs, raisins, etc. imported from Africa and Asia to Europe in increasing amounts and possibly irradiated before transportation.

Dried fruits contain crystalline sugars in which radicals induced by radiation can be effectively stabilized and then measured by EPR. In order to introduce a new European standard EN 13708:2003 [5], the inter-comparison studies were carried out to prove the stability and intensity of radiation-induced EPR signals in tropical fruits. The results of the first test in 1992 were not satisfactory. Twenty-six dried mango and fig fruits were tested in 11 laboratories, and up to 10 samples were incorrectly identified [13]. In 1996, the second test was organized, in which 17 laboratories took part in analysing 184 dehydrated fig and mango fruits [18]. Now, the correct identification was very high - only two fig samples were wrongly recognized. Therefore, the European Standardization Committee accepted those inter-comparison studies as a validation of the EPR identification method for irradiated fig and mango fruits, announcing its decision in the European standard 13708:2003 [5, 19].

Among the methods used for identification of irradiated food, the EPR technique is the most sensitive. However, the majority of radiation-induced radicals in food products lives are too short to be used for control of irradiated food. The exceptions are the EPR signals produced by ionizing radiation in bones, which remain stable for centuries. The signal is assigned to $\mathrm{CO}_{2}^{-}$anion radicals trapped in the bone mineral - hydroxyapatite. $\mathrm{CO}_{2}^{-}$signal is used in dosimetry of ionizing radiation or even for dating of archaeological skeletons. The radiation-induced radicals in fruit sugars, nut shells, and pepper powders are less stable and make EPR identification less reliable.

\section{Inter-comparison studies organized by the Spanish Agency for Food Safety and Nutrition and Food National Spanish Centre}

In the last decade, the Spanish Agency for Food Safety and Nutrition (AESAN) and Food National Spanish Centre (CNA) took the initiative in the organization of inter-laboratory tests for food irradiation control. In 2010, 26 samples were sent to the participating laboratories to be studied by using TL, PSL, and EPR methods. The samples of basil, mint, pole, and dill were to be examined by TL, while samples of paprika and curry by PSL spectroscopy. The products containing cellulose, crystalline sugars, or hydroxyapatites were selected for EPR measurements. Altogether, 20 samples of capsicum, paprika, curry, curry cayenne, dried onion, goat, hazelnut, raisins green and black, chicken, pistachio, walnut, pepper, paprika green, four types of mollusk shells, and two types of fish bones were analysed by EPR spectroscopy. The samples measured with the use of TL and PSL were correctly identified, whereas the EPR tests revealed serious discrepancies. There were no problems with the identification of irradiated bones, raisins, nuts, or mollusk shells; however, among samples of spices and herbs such as pepper, curry, dried onion, and capsicum, only half of the samples were correctly identified.

In the next test organized in 2012, 12 samples were tested by EPR (quail bone, pig bone, raisins, curry, cockle shells, mussel shells, pistachio shells), three samples by TL (rosemary leaf, tarragon), and two by PSL (green tea, turmeric) spectroscopy. The samples were analysed by 19 laboratories from various European countries such as Italy, Romania, Poland, Germany, France, and Spain, and in general, the results of inter-comparison studies were very satisfactory. All the samples were correctly identified by all laboratories except the curry sample irradiated with $5 \mathrm{kGy}$, which was assigned to the non-irradiated category by five laboratories.

In the inter-comparison test organized in 2015, 22 laboratories took part in testing 10 samples by EPR (paprika, pistachio shells, raisin, chicken bone, turbot bone), two samples by TL (dried mushrooms, sunflower seeds), and two samples by PSL (dried tomatoes, sesame) spectroscopy. For samples tested by PSL spectroscopy, all laboratories got correct results. Only one result was false for samples measured by EPR spectroscopy - one laboratory did not identify irradiated pistachio shells. The second false result was concerned with sunflower seeds analysed by TL spectroscopy.

The most recent inter-comparison test organized by AESAN and CNA took place in 2018 with participation of 19 European laboratories from Italy, Germany, France, Spain, Romania, Turkey, Croatia, and Poland. The samples of pistachio, hazelnut, chicken bone, dried kiwi, and dried mango were studied by EPR spectroscopy, whereas oregano and dried tomato by TL spectroscopy and chamomile and chickpeas by PSL spectroscopy. All laboratories correctly identified the samples analysed by TL and PSL methods. The EPR identification this time was less satisfactory - three laboratories did not recognize irradiated hazelnut samples, and one testing team did not identify irradiated chicken bone. After each inter-comparison study, the AESAN and CNA published the results in the bulletin "Final report of the inter-comparison exercise for quality assurance on TL, PSL, and EPR irradiated food detection methods" $[20,21]$, which was sent only to the participating laboratories. In the report, authors focused their interest mainly on statistical analysis of results and did not try to discuss why the identification of some samples was less reliable than that of the others and which identification methods were the best for specific alimentary products.

However, the results presented above clearly show that the participating European laboratories 
had already won necessary analytical experience with the identification of irradiated food.

\section{The participation of the laboratory in the inter-com- parison tests for detection of irradiated food}

Since the early 1990s, the Laboratory for Detection of Irradiated Food (LDIF) in the Institute of Nuclear Chemistry and Technology (INCT, Warsaw, Poland) had participated in numerous inter-comparison tests $[19,22-26]$. Here, however, we are going to present the results of the most recent tests [20]. In 2015, the CNA sent for identification eight different food samples, which were unirradiated and irradiated in a Cs-137 source with doses in the range of $0.5-5 \mathrm{kGy}$.

The samples of dried onions, nut shells, raisins, shells of shrimps, and mollusks [20] were assigned for EPR studies, whereas samples of hot pepper were tested by PSL spectroscopy and sweet pepper by TL spectroscopy. EPR spectroscopy at the INCT was carried out using a Bruker EMX Plus spectrometer, with setting parameters according to the European standards: EN 1786, EN 1787, and EN 13708. The samples before measurements were dried at the temperature $40^{\circ} \mathrm{C}$ for $24 \mathrm{~h}$ and then placed in spectrosil thin-wall tubes, which do not give any EPR signal. The LDIF identified correctly five samples using the EPR method; only shrimp shells irradiated with $1 \mathrm{kGy}$ were falsely recognized as non-irradiated ones. Six other laboratories made similar mistakes. The mistakes were probably due to the fact that shrimp shells are not structurally homogenous and some shell parts contain less mineralized tissue than others. Since the paramagnetic centers generated by radiation are stabilized only in the mineral part of shells, it appears that the EPR identification of irradiated shrimps is not a completely reliable method. There was no problem with EPR identification of other samples. The EPR spectra of irradiated dried onions and raisins are intense enough to assign them to the radicals generated by radiation. Figure 1 presents the EPR spectra of the Morocco raisin sample irradiated with a dose of $0.5 \mathrm{kGy}$. The signal originates from radicals induced by radiation in the crystalline domains of glucose or fructose, which appear in dried fruit and can be easily detected even 12 months after irradiation.

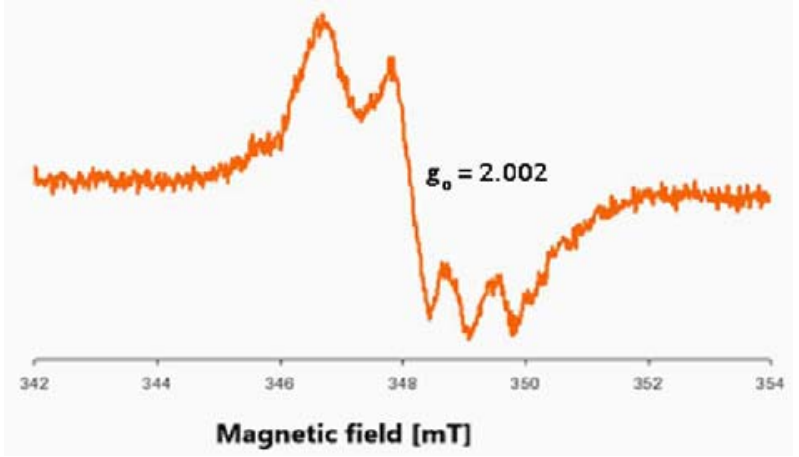

Fig. 1. Multiline EPR signal of dried Morocco raisin irradiated with the dose of $0.5 \mathrm{kGy}$. Unirradiated raisin does not show any EPR signal. $g_{0}$ corresponds to geometric centre of multi-component signal.
Table 1. Results of the PSL (for hot peppers) and TL (for sweet peppers) examination of minerals isolated from the dried peppers

\begin{tabular}{|c|c|c|c|}
\hline \multirow{2}{*}{$\begin{array}{c}\text { Name } \\
\text { of sample }\end{array}$} & \multicolumn{2}{|c|}{ TL intensity $\left(150-250^{\circ} \mathrm{C}\right)$} & \multirow{2}{*}{$\begin{array}{c}\text { Glow ratio } \\
\text { A/B }\end{array}$} \\
\hline & Glow A & Glow B & \\
\hline Hot pep & 107664 & 2446361 & 0.437 \\
\hline Sweet peppers & 8271517 & 9420144 & 0.878 \\
\hline
\end{tabular}

PSL, photoluminescence; TL, thermoluminescence.

Two samples of hot and sweet pepper analysed by TL and PSL spectroscopy, respectively, were clearly identified as irradiated. The application of luminescence techniques for the identification of irradiated food is based on the measurement of free electrons produced by ionizing radiation and trapped at the imperfections in the crystal lattice of mineral solids. Heating of the crystallites in the sample frees some of these electrons from the traps. The process is associated with the intensity of the light emitted, which depends on radiation dose. For TL measurements, the minerals, which usually are small sand grains, have to be removed from the food sample by a tedious and time-consuming extraction process. Chemical treatment is not necessary for PSL analysis in which electrons are released by photostimulation. However, the sensitivity of this method is distinctly lower, and owing to the low sensitivity, the PSL technique not very useful when food products are irradiated with low doses.

According to the EN 1788 standard, the identification of irradiated food by the TL technique requires two measurements - the first one is a commercial sample and the second one is the same sample but additionally irradiated with a dose of $1 \mathrm{kGy}$. At the INCT, the additional irradiations were carried out using Gamma Chamber 5000 produced in India. The RIS $\varnothing$ reader TL-DA-20 was used for TL analysis, and the SURRC reader manufactured in Scotland was used for PSL measurements.

Table 1 shows the glow intensities of the original samples during heating at $250^{\circ} \mathrm{C}$ (A) and samples additionally irradiated with dose of $1 \mathrm{kGy}$ (B). An $\mathrm{A} / \mathrm{B}$ ratio higher than 0.1 indicates unequivocally that the sample was irradiated.

In 2018, CNA sent the samples of pistachio nut, hazelnut, chicken bone, dried kiwi, and mango irradiated with an electron beam at a dose of $1 \mathrm{kGy}$ to the participating laboratories for identification using EPR spectroscopy [21]. Among them, only the sample of hazelnut was incorrectly assigned as unirradiated. The EPR singlet with $\mathrm{g}_{0}=2.004$ of irradiated hazelnuts (Fig. 2) that is assigned to cellulose radical is not quite stable and decays with a half-life of 20 days. Since the test samples were measured three months after irradiation, the intensity of the EPR signal decayed completely. Since five other laboratories did not identify the irradiation of hazelnuts, it is clearly seen that EPR identification of irradiated hazelnut is not a reliable method. Unirradiated samples do not show any EPR signal.

On contrary, the EPR signal in irradiated bones (Fig. 3) is exceptionally stable. It is an anisotropic singlet with $\mathrm{g}_{\|}=2.002$ and $\mathrm{g}_{\perp}=1.997$ derived from 


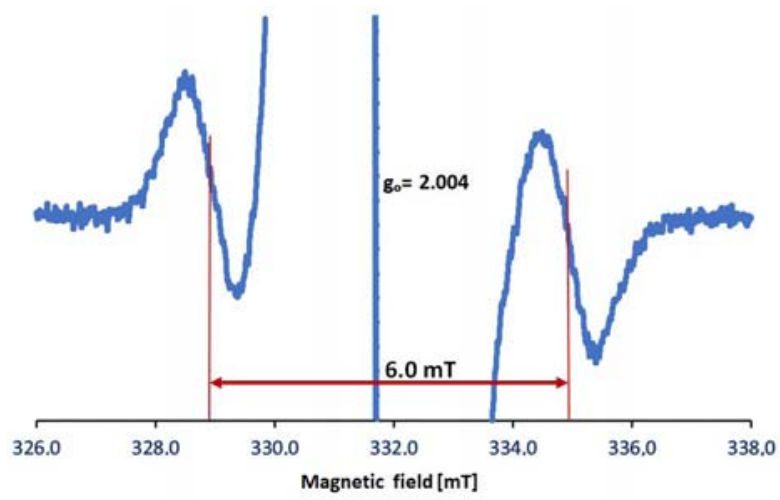

Fig. 2. EPR signal of irradiated sample of matured hazelnut shells harvested in Polish farms. Two satellite lines of isotropic triplets distanced by $6.0 \mathrm{mT}$ assigned to cellulose radical are considered the evidence of radiation treatment. The central line of the cellulose triplet is superimposed by a strong native singlet and overgrows the frames of the figure.

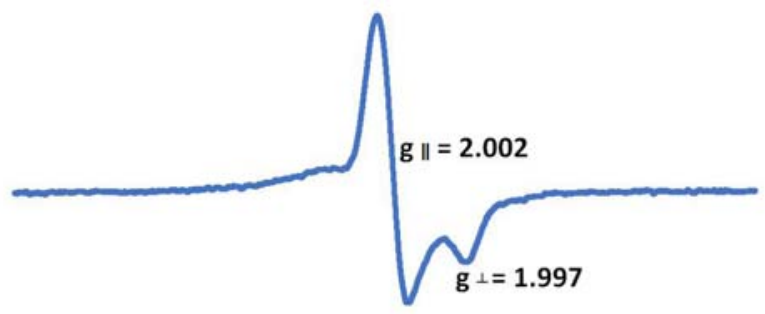

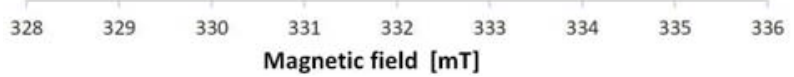

Fig. 3. EPR signal of chicken bone sample, irradiated with $0.5 \mathrm{kGy}$, assigned to a singlet of axial symmetry of $\mathrm{CO}_{2}^{-}$ion radical.

a $\mathrm{CO}_{2}^{--}$radical anion trapped in a crystalline network of hydroxyapatite - the major mineral constituent of bone tissues. Its stability makes it possible to use bone samples as radiation dosimeters [13, 22, 24] and as paramagnetic labels for dating of human remains [23, 27]. For identification of irradiated meat containing bones, the EPR spectroscopy is the first method of choice.

\section{Conclusions and perspectives}

Owing to the initiative of the Federal Institute for Health Protection of Consumers and Veterinary Medicine (Germany) and the Spanish Agency for Food Safety and Nutrition (Spain), the intercomparison studies for control of irradiated food are being regularly carried out in Europe for the last 25 years. To our knowledge, in the last decade of the previous century, 17 tests were organized, in which 478 samples of various food products were analysed in 23 laboratories from 14 European countries. In the next two decades, eight rounds of inter-comparison tests had been conducted with participation from seven to 22 laboratories. Primarily, three main groups of food samples - bones, dry fruits, and nuts - had been analysed.

The main goal of the inter-comparison studies was to check the methodology and analytical skills of the participating laboratories. Additionally, the results of tests organized in the 1990s played a crucial role in the preparation of European Standards. First of all, they made it possible to choose the reliable identification techniques for individual food products and to describe precisely the analytical methodology. The later tests organized by Spanish agencies had also an additional task of scrutinizing and confirming the effectiveness of the identification of irradiated food based on EU standards. The obtained data allowed specification of the changes which should be introduced into the European Standards and Directives in the future $[28,29]$. The inter-comparison studies proved also that the methodology used in European laboratories to control irradiated food reached the high professional level, guaranteeing reliable results.

The Laboratory for Detection and Irradiated Food started participating in European inter-comparison tests in 2008 and took part in six tests. About 27 different food samples were sent to the LDIF for identification, and only three samples were incorrectly assigned. The contribution in the inter-comparison tests allowed us to prove the limits of applied identification methods and to select the best methodologies for specific products. It was also very helpful in the process of laboratory certification, which resulted in the substantial increase of orders from abroad. During 2010-2018, the majority of orders for identification of irradiated food samples came from foreign clients.

In the last couple of years, the assortment of analysed products changed very much. Earlier, the LDIF identified mostly the irradiation of herbs, spices, and seafood, from which the separation of minerals for TL or solids for EPR detection was relatively simple. Nowadays, the diet supplements and biopharmaceuticals are irradiated on an increasing scale. For them, sophisticated extraction methods have to be applied in order to separate minerals. Also, usually, the amount of separated minerals is much smaller, which creates a real analytical challenge.

The other problem is due to the application of lower irradiation doses by food producers than those recommended by Codex Alimentarius [1]. In order to reduce the cost of treatment, the combined methods, i.e., radiation-thermal pasteurization, are more frequently used. The food is first pasteurized or lyophilized and then irradiated with a dose reduced even down to $50 \%$ in comparison with doses required by European Standards.

The numerous components of diet supplements which are present in the European market come from Asia, where they are decontaminated in that way.

This requires a new approach to the identification of irradiated food by the development of more sensitive detection methods and more efficient methods for mineral separation. To solve those problems, there is an urgent need to organize the inter-comparison studies for leading analytical laboratories. The aim of those exercises should concern the new methodology for TL, PSL, and EPR techniques for identification of complex, multi-component food samples irradiated with lower doses than used so far. 
The European Commission has stated their opinion that recommendations in Codex Alimentarius are less and less adequate to world trends of food irradiation; this statement gave rise to the commencement of preliminary works on new legal regulations. At the beginning of 2020, the Commission sent a questionnaire to food producers and specialists in the control of irradiated food concerning the evaluation of EU's regulatory framework for irradiation of food. The Commission wanted to know the opinions from all EU countries concerning the present regulations on food irradiation, especially on the effectiveness of monitoring systems and importance of reporting systems for dissemination of radiation technologies for food preservation. The response from the representatives of each country to that questionnaire will be an essential input to the public consultation for improvement of EU law regulations for irradiation of food [30]. Based on the information collected from the questionnaire together with other data, the Commission is going to propose suitable changes in EU regulation.

The new inter-comparison studies dedicated to the identification of complex food products such as diet supplements or biopharmaceuticals that had been irradiated may have significant influence on the modification of European regulations concerning the food irradiation and the control of irradiated food products.

\section{ORCID}

G. P. Guzik (1) http://orcid.org/0000-0001-9946-3133 J. Michalik (D) http://orcid.org/0000-0001-6609-1337

\section{References}

1. FAO/WHO. (2003). General Standard for Irradiated Foods. Codex Alimentarius 106-1983. Rev. 1-2003.

2. International Atomic Energy Agency. (1989). Conference on Acceptance, Control of and Trade in Irradiated Food. Conference proceedings, Geneva, 12-16 December 1988. Vienna: IAEA.

3. European Committee for Standardization. (2002). Foodstuffs - Thermoluminescence detection of irradiated food from which silicate minerals can be isolated. EN 1788:2002. Brussels: European Committee for Standardization.

4. European Committee for Standardization. (2009). Foodstuffs - Detection of irradiated food using photostimulated luminescence. EN 13751:2009. Brussels: European Committee for Standardization.

5. European Committee for Standardization. (2003). Foodstuffs - Detection of irradiated food containing crystalline sugar by ESR spectroscopy. EN 13708:2003. Brussels: European Committee for Standardization.

6. European Committee for Standardization. (2001). Foodstuffs - Detection of irradiated food containing cellulose by ESR spectroscopy. EN 1787:2001. Brussels: European Committee for Standardization.

7. European Committee for Standardization. (2000). Foodstuffs - Detection of irradiated food containing
bone-Method by ESR spectroscopy. EN 1786:2000. Brussels: European Committee for Standardization.

8. Sanderson, D. C. W., Schreiber, G. A., Wagner, U., Leffke, A., Helle, N., Ammon, J., \& Carmichael, L. (1991). A European trial of TL detection of irradiated herbs and spices. Scottish Universities Research Reactor Center Report to BCR.

9. Schreiber, G. A., Helle, N., \& Bogl, K. W. (1995). An inter-laboratory trial on the identification of irradiated spices, herbs and spice-herbs mixtures by thermoluminescence analysis. Journal of AOAC International, 78(1), 88-93.

10. Schreiber, G. A., Helle, N., Schulzki, G., Linke, B., Spiegelberg, A., Mager, M., \& Bogl, K.W. (1996). Interlaboratory tests to identify irradiation treatment of various foodstuffs via gas chromatographic detection of hydrocarbons, ESR spectroscopy and TL analysis. In C. H. McMurray, E. M. Stewart, R. Gray \& J. Pearce (Eds.), Detection methods for irradiated foods - current status (pp. 98-107). Cambridge: Royal Society of Chemistry.

11. Sanderson, D. C. W., Carmichael, L., Naylor, J. D., \& Fisk, S. (1997). An international collaborative blind trial of thermoluminescence detection of irradiated shellfish. Scottish Universities Research Reactor Center Report to MAFF.

12. Schreiber, G. A., Wagner, U., Ammon, J., Sanderson, D. C. W., Zoost, C., \& Bogl, K. W. (1997). An interlaboratory on the identification of irradiated potatoes and on the estimation of applied doses by thermoluminescence analysis. Report of the Federal Institute for Health Protection of Consumers and Veterinary Medicine. Berlin: Bundesinstitut fur gesundheitlichen Verbraucherschutz und Veterinarmedizin. (BgVVHefte 13/1997).

13. Raffi, J. (1992). Electron spin resonance intercomparison studies on irradiated foodstuffs. BSR-Information. Luxembourg: Commission of the European Communities. (Report EUR/13630/en).

14. Sanderson, D. C. W., Carmichael, L., \& Fisk, S. (1998). Establishing luminescence methods to detect irradiated foods. Food Sci. Techn. Today, 12(2), 97-102.

15. Raffi, J., Stevenson, M. H., Kent, M., Thiery, J. M., \& Belliardo, J. -J. (1992). European intercomparison on electron spin resonance identification of irradiated foodstuffs. Int. J. Food Sci. Technol., 27, 111-124.

16. Raffi, J., Fakirian, A., \& Lesgards, G. (1994). Comparison between electron spin resonance and thermoluminescence in view of identification of irradiated aromatic herbs. Annual Flamand Experimental Chemistry, 87, 125-133.

17. Linke, B., Helle, N., Ammon, J., Ballin, U., Delincee, H., Stewart, E., Vater, N., Vreden, N., Bogl, K. W., \& Schreiber, G. A. (1995). Elektronenspinresonanzspectroskopische Untersuchungen zur Idetifizierung bestrahlter Krustentiere und Gewurze: Durchfuhrung eines Ringversuches an Nordseekrabben, Kaisergranat und Paprikapulover. Berlin: Federal Institute for Health Protection of Consumers and Veterinary Medicine. (BgVV-Heft 09).

18. Helle, N., Linke, B., Schroeiber, G. A., \& Bogl, K. W. (1996). Nachweis der gamma Bestrahlung von Trockenfruechten. Bundesgesundheitsblatt, 35, 179. 
19. Rafii, J., Stachowicz, W., Migdał, W., Barabassy, S., Kalman, B., Yordanov, N., Andrade, E., Prost, M., \& Callens, F. (1998). Establishment of an eastern network of laboratories for identification of irradiated food-stuffs. Final report of Copernicus Concerted Action. (CIPA-CT94-0134, CCE).

20. Barea Sanchez, M. (2015). Final report of the intercomparison exercise for quality assurance on $T L$, PSL and EPR irradiated food detection methods (6th round). Spain: Servicio de Toxicologia Alimentaria et Centro Nacional de Alimentacion.

21. Spanish Agency for Consumer Affairs, Food Safety and Nutrition, \& National Food Center. (2018). Intercomparison exercises for quality assurance on physical methods for irradiated food detection (8th round). Spain: AECOSAN/CNA.

22. Raffi, J. (1992). Electron spin resonance intercomparison studies on irradiated foodstuffs. Final report of Contract No 5348/1/5/340/90/4/BCR-F (10). Commission of the European Communities.

23. Desrosiers, M. F. (1992). Coordinated research program on analytical detection methods for irradiation treatment of foods ADMIT. In Second Research Coordination Meeting. Budapest, Hungary 1992.

24. Desrosiers, M. F. (1994). Report on activities for the coordinated research program on analytical detection methods for irradiation treatment of foods ADMIT. In Third Research Coordination Meeting, Belfast, Northern Ireland 1994.

25. Stewart, E. M., \& Kilpatrick, D. J. (1994). An international collaborative blind trial using ESR spec- troscopy to detect irradiated crustacea. Ministry of Agriculture, Fisheries and Food MAFF. (UK 1994/5).

26. Guzik, G. P., Stachowicz, W., Cutrubinis, M., \& Sulea, C. (2009). Polish-Romanian intercomparison study on the EPR and PSL detections of irradiated foodstuffs. In Annual Report INCT 2008 (pp. 110-112). Warsaw: Institute of Nuclear Chemistry and Technology.

27. Stachowicz, W., Burlińska, G., Michalik, J., Dziedzic-Goclawska, A., \& Ostrowski, K. (1996). EPR spectroscopy for the detection of foods treated with ionising radiation. In C. H. McMurray, E. M. Steward, R. Grey \& J. Pearce (Eds.), Detection methods for irradiated foods. Current status (pp. 23-44). Cambridge: The Royal Society of Chemistry.

28. Council of the European Union, European Parliament. (1999). Directive 1999/2/EC of the European Parliament and of the Council on the approximation of the laws of the Member States concerning foods and food ingredients treated with ionizing radiation. Publications Office of the European Union.

29. Council of the European Union, European Parliament. (1999). Directive 1999/3/EC of the European Parliament and of the Council on the establishment of a Community list of foods and food ingredients treated with ionizing radiation. Publications Office of the European Union.

30. European Commission. (2020). Evaluation of the EU's regulatory framework for irradiation of food. A questionaire. European Food Safety Authority. 